\title{
PELATIHAN DAN PENYULUHAN TATA KELOLA ORGANISASI BAGI UMKM CV. BONANZA DI BOYOLALI UNTUK MENINGKATAN KINERJA PERUSAHAAN
}

\author{
Edwin Zusrony, Ahmad Zainudin, Edy Jogatama Purhita, Agustinus Budi Santoso, \\ Dewi Widyaningsih, Indra Ava Dianta \\ Sekolah Tinggi Elektronika \& Komputer (STEKOM) \\ *edwin.zusrony@gmail.com
}

\begin{abstract}
ABSTRAK
Perkembangan dunia usaha terjadi begitu masif dan cepat, dimana seorang pengusaha harus selalu belajar cepat menghadapi segala perubahan yang terjadi. Salah satu cara yang dapat dilakukan adalah mengadakan pelatihan terhadap pengelolaan organisasi dalam dunia usaha agar dapat menghadapi tantangan zaman. Pelatihan oleh Tim dosen STEKOM Semarang dalam rangka tata kelola organisasi bagi UMKM CV. Bonanza di Kab. Boyolali, Jawa Tengah terkait dengan beberapa materi seperti strategi memperoleh pinjaman modal kerja dari perbankan, teknik pembuatan laporan keuangan bagi UMKM, perancangan website pada UMKM, perancangan promotion content pada UMKM, teknik manajemen periklanan, serta perancangan media periklanan. Pelatihan dan penyuluhan ini menjadi langkah nyata dalam mengaplikasikan ilmu yang dimiliki oleh para dosen untuk pengabdian masyarakat sebagai salah satu dari kegiatan Tridharma Perguruan Tinggi. Dalam melakukan pelatihan dan penyuluhan, kami menggunakan metode presentasi interaktif dan sesi tanyajawab untuk meningkatkan pemahaman terhadap materi yang disampaikan.
\end{abstract}

Kata Kunci: Tata Kelola Organisasi, UMKM, Kinerja Organisasi

\begin{abstract}
The development of the business world happens so massive and fast, where an entrepreneur must always learn quickly to face all the changes that occur. One way that can be done is to conduct training on organizational management in the business world in order to face the challenges of the times. Training by STEKOM Semarang lecturer team in the framework of organizational governance for MSME CV. Bonanza in Kab. Boyolali, Central Java is related to several materials such as strategies for obtaining working capital loans from banks, techniques for making financial reports for MSMEs, designing websites at MSMEs, designing promotional content at MSMEs, advertising management techniques, and designing advertising media. This training and counseling is a concrete step in applying the knowledge possessed by lecturers to community service as one of the Tridharma of Higher Education activities. In conducting training and counseling, we use interactive presentation methods and question sessions to increase understanding of the material presented.
\end{abstract}

Keywords: Organizational Governance, Small and Medium Enterprises, Company Performance 


\section{PENDAHULUAN}

Berkembangnya perekonomian suatu negara sangat dipengaruhi seberapa besar jumlah pengusaha atau wirausahawannya. Hal ini menjadi indikator meningkatnya pertumbuhan ekonomi suatu negara yang dilihat dari sektor perdagangan seperti negara China, Singapura, dan India. Saat ini Indonesia mulai mengejar ketertinggalan dalam menggenjot sektor ekonomi dengan membangun dan meningkatkan sektor ekonomi kreatif.

Pertumbuhan dunia usaha di era revolusi industri 4.0 sangat pesat dengan dukungan infrastruktur dan peningkatan kompetensi SDM di Indonesia. Dunia usaha yang mengalami pertubumbuhan yang pesat ini juga didukung oleh sarana dan prasaranan yang disediakan oleh pemerintah untuk mendukung meningkatknya produktifitas usaha. Kendala yang dihadapi dalam dunia usaha, khususnya UMKM adalah keterbatasan modal. Modal menjadi faktor penting dalam peningkatan kapasistas usaha, selain kompetensi SDM, sehingga diperlukan upaya untuk melakukan edukasi kepada masyarakat di dunia usaha. Dalam meningkatkan pengetahuan masyarakat UMKM dalam kemudahan dalam memperoleh modal kerja, maka diperlukan penyuluhan dan pelatihan tentang teknik dan strategi dalam memperoleh kredit pembiayaan modal kerja dari perbankan.

Usaha kecil merupakan salah satu ujung tombak perekonomian negara Indonesia, sektor ekonomi kreatif berkembang pesat dalam beberapa industri UMKM. Peran UMKM dalam menjadi motor penggerak perekonomian nasional sangatlah signifikan dalam satu dekade terakhir. Munculnya banyak pengusaha-pengusaha muda membuat sektor UMKM menjadi komoditi yang menjanjikan.

Sebagai langkah kepedulian dan pengamalan salah satu Tridharma Perguruan Tinggi, beberapa dosen STEKOM Semarang mencoba memberikan sedikit kontribusi dalam kegiatan pelatihan dan penyuluhan terhadap salah satu UMKM di wilayah Boyolali, Jawa Tengah. Kegiatan ini dilakukan berdasarkan hasil pengamatan masih minimnya pengetahuan oleh pengusaha UMKM beserta anggotanya tentang tata kelola organisasi UMKM, khususnya terkait kesulitan dalam peningkatan kapasitas usaha. Dengan adanya program pelatihan serta penyuluhan ini diharapkan para pengusaha UMKM dapat memahami dan mengimplementasikan ilmu dan informasi yang diperoleh.

Pemilihan program penyuluhan dan pelatihan dalam tata kelola organisasi bagi UMKM didasarkan atas kebutuhan serta permintaan pimpinan UMKM CV. Bonanza pada saat anggota Tim PPM mengadakan kunjungan ke tempat usaha pemilik dalam tahapan 
pra survei. Tekait dengan hal tersebut, Tim dosen STEKOM Semarang memandang perlu pelatihan dan penyuluhan bidang tata kelola organisasi UMKM, untuk diselenggarakan.

\section{MASALAH}

Peran UMKM di Indonesia sebagai penggerak perekonomian nasional tidak dapat dipungkiri membuat banyak orang bergelut menjadi wirausahawan. Tetapi masih sangat banyak UMKM yang belum bisa mengembangkan bisnisnya dikarenakan berbagai kendala. Beberapa kendala yang sering dihadapi oleh pengusaha UMKM saat ini salah satunya kurangnya konsumen dalam mengenal produk UMKM, kebutuhan modal, pembuatan laporan keuangan yang baik, pemasaran, tidak adanya merek produk, dll. Berdasarkan beberapa permasalahan tersebut, beberapa dosen STEKOM Semarang mencoba untuk memberikan pelatihan dan penyuluhan kepada salah satu UMKM yaitu CV. Bonanza di wilayah Kab. Boyolali, Jawa Tengah untuk meningkatkan tata kelolanya agar dapat meningkatkan kapasitas usaha beserta kompetensi pemilik dan karyawan.

\section{METODE}

Dalam pelaksanaan kegiatan pelatihan dan penyuluhan di UMKM CV. Bonanza di Kab. Boyolali, Jawa Tengah menggunakan beberapa metode dalam penyampaian materi. Hal ini dilakukan oleh para penmateri agar proses penerimaan materi dapat terserap secara optimal dan diharapkan ada feedback dari peserta pelatihan. Metode yang digunakan dalam pelatihan dan penyuluhan ini adalah sebagai berikut :

\subsection{Metode Pelaksanaan}

a. Presentasi Interaktif

Presentasi interaktif dipilih oleh tim dosen dalam menyampaikan gagasan atau konsep tata kelola organisasi pada UMKM dengan konten yang menarik serta mudah dipahami oleh seluruh peserta kegiatan pengabdian masyarakat. Dalam presentasi interaktif diharapkan antara peserta dan pemateri terjadi interaksi serta komunikasi dua arah, sehingga penyerapan materi akan lebih cepat dipahami. Beberapa materi yang diberikan pada kegiatan ini antara lain: strategi memperoleh pinjaman modal kerja dari perbankan, teknik pembuatan laporan keuangan bagi UMKM, perancangan website pada UMKM, perancangan promotion content pada UMKM, teknik manajemen periklanan, 
serta perancangan media periklanan.

b. Pelatihan

Metode yang digunakan oleh tim dosen dari STEKOM dengan memberikan tugas sederhana dari materi pelatihan (seperti menyusun laporan keuangan sederhana) serta melakukan pendampingan pada peserta sehingga ada feedback yang akan didapatkan untuk evaluasi kegiatan.

\subsection{Teknis Pelaksanaan}

Teknis Pelaksanaan pada kegiatan pelatihan dan penyuluhan dilakukan secara bertahap selama 2 hari dengan beberapa pokok materi sebagai berikut :

a. Strategi memperoleh pinjaman modal kerja dari perbankan

b. Teknik pembuatan laporan keuangan bagi UMKM

c. Perancangan website pada UMKM

d. Perancangan promotion content pada UMKM

e. Teknik manajemen periklanan

f. Perancangan media periklanan

\section{Presentasi}
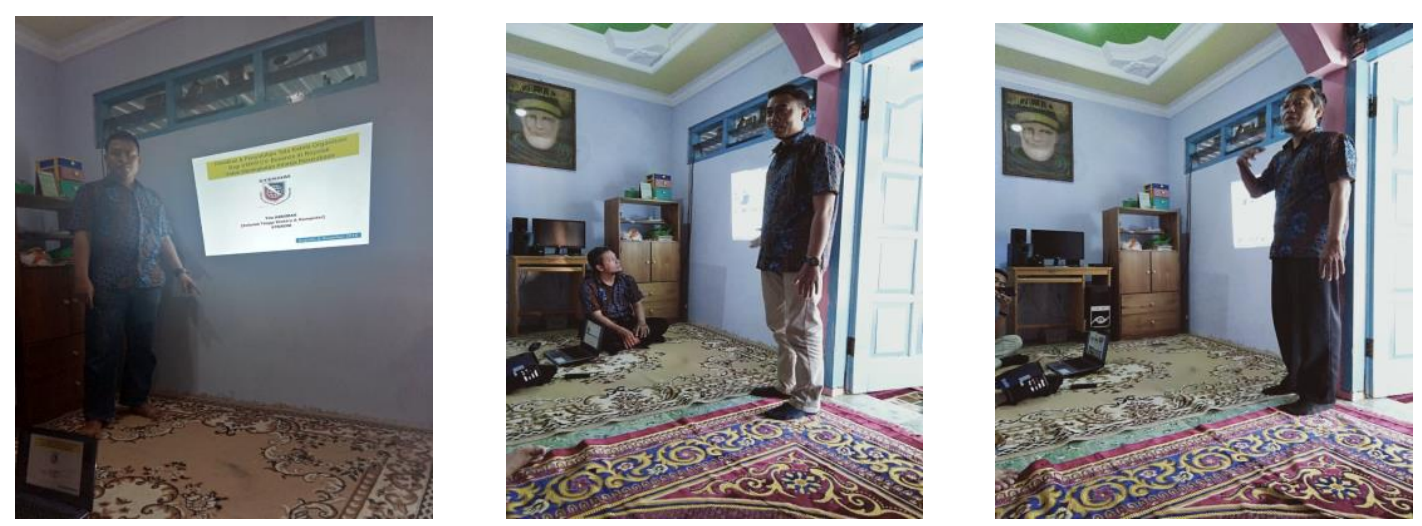


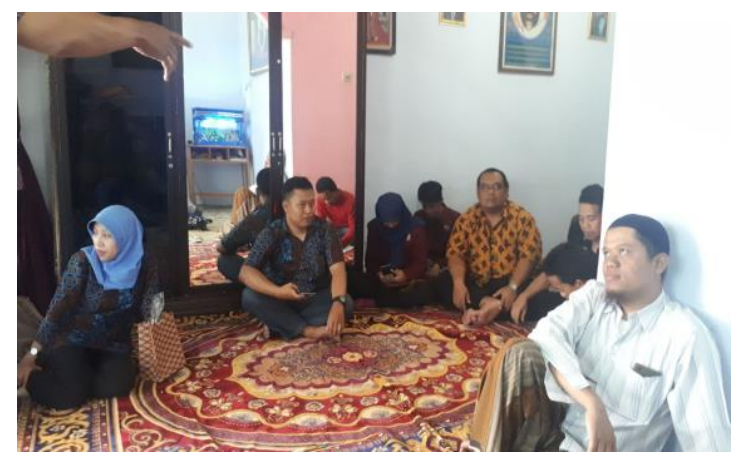

Gambar 1. Penyampaian Materi Tata Kelola Organisasi pada UMKM

\section{Peninjauan Lokasi Usaha}
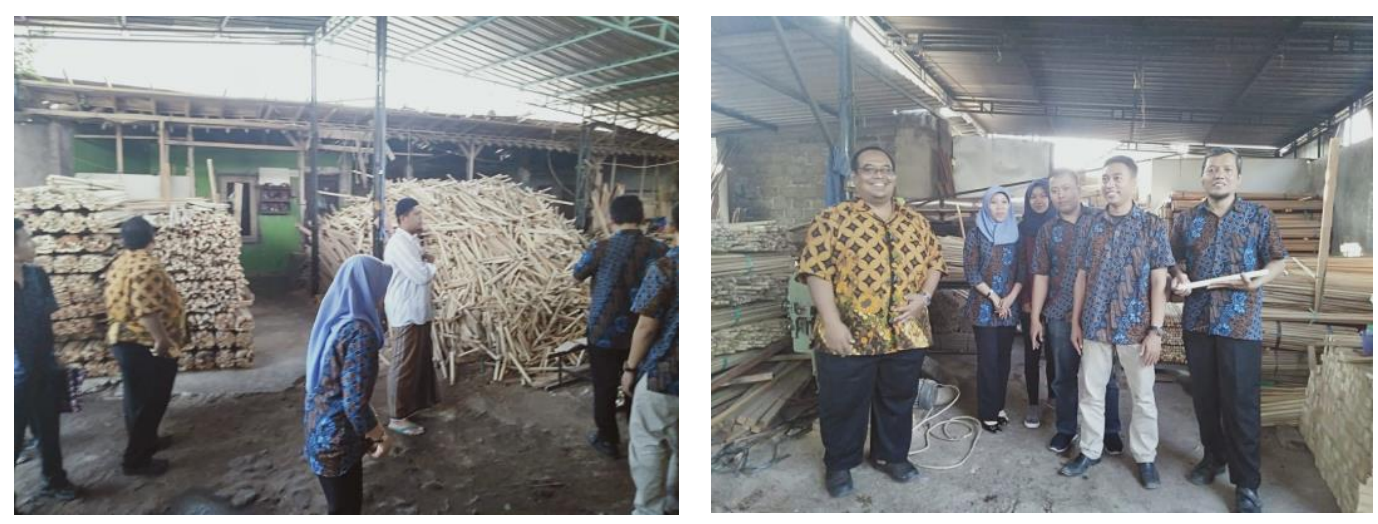

Gambar 2. Meninjau Lokasi Usaha

\subsection{Tempat, Waktu dan Pelaksanaan Kegiatan}

Tempat : Rumah pemilik CV. Bonanza di Mojosongo Boyolali

Waktu : Sabtu, tanggal 8 dan 15 Desember 2018

Pelaksanaan Kegiatan : Pukul 08.00 s/d 12:00 WIB. 


\section{HASIL DAN PEMBAHASAN}

Pelaksanaan kegiatan pelatihan dan penyuluhan tata kelola organisasi bagi UMKM CV. Bonanza di Boyolali yang dilaksanakan oleh Tim Dosen dari STEKOM. Total jumlah peserta dalam kegiatan ini diikuti sebanyak 18 orang. Salah satu output dari pelatihan dan penyuluhan di CV. Bonanza di Boyolali berupa website UMKM dengan alamat URL:

https://cvbonanza.000webhostapp.com/.
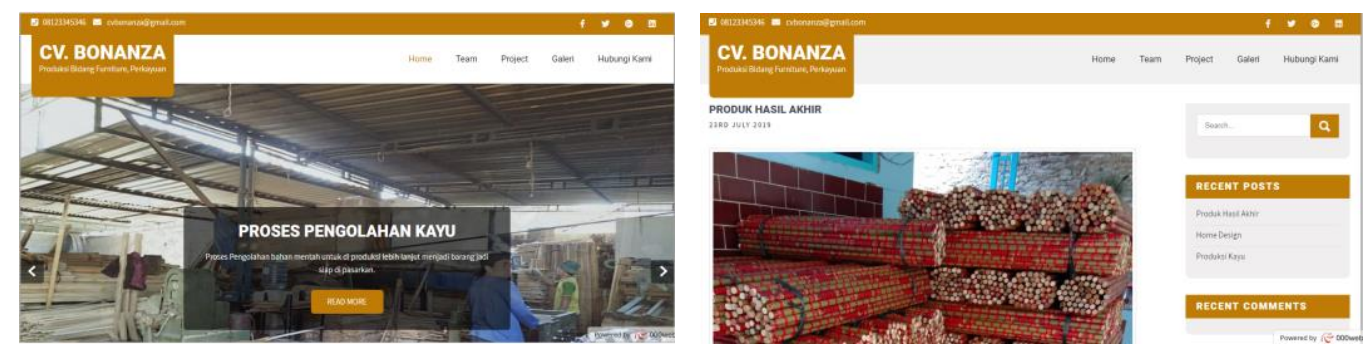

Gambar 3. Hasil Pembuatan Website UMKM

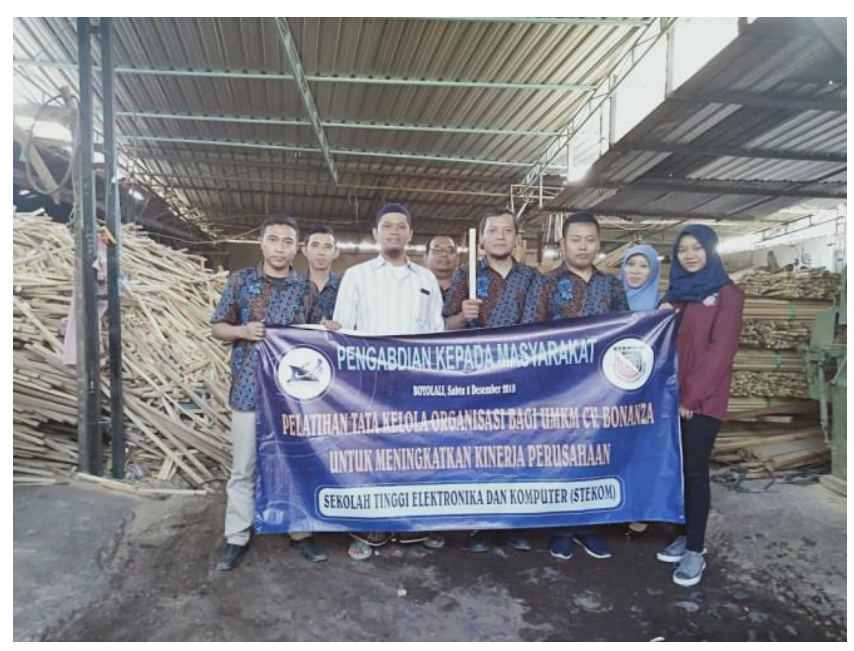

Gambar 4. Penutupan Kegiatan Pelatihan dan Penyuluhan

Hasil dari kegiatan pelatihan dan penyuluhan tata kelola organisasi bagi UMKM CV. Bonanza di Kab. Boyolali, Jawa Tengah dengan beberapa serangkaian kegiatan diantaranya: materi tentang strategi memperoleh pinjaman modal kerja dari perbankan, teknik pembuatan laporan keuangan bagi UMKM, perancangan website pada UMKM, perancangan promotion content pada UMKM, teknik manajemen periklanan, serta perancangan media periklanan. Dengan adanya pelatihan serta 
penyuluhan ini maka para karyawan beserta pemilik usaha dapat memahami pengelolaan organisasi UMKM dengan baik dan benar. Respon serta feedback dari para peserta pelatihan sangatlah bagus, hal ini dapat dilihat dari beberapa pertanyaan yang muncul terkait dengan beberapa materi yang disampaikan oleh tim dosen STEKOM Semarang.

\section{KESIMPULAN}

Perubahan era digital saat ini menjadi hal yang harus diperhatikan semua stakeholders dalam menjawab tantangan zaman, khususnya sektor usaha kecil. Industri UMKM harus berkembang mengikuti era perkembangan zaman dengan terus mau berubah serta meningkatkan tata kelola organisasi untuk meningkatkan kompetensi dan kapasitas usaha. Nilai pencapaian dari pelatihan ini dapat dilihat dari antusiasme para peserta untuk mau belajar hal-hal baru, khususnya dalam peningkatan kompetensi atau hard skills.

\section{DAFTAR PUSTAKA}

Metode, I., Sistem, P., Kredit, P., \& Bank, P. (2018). Implementasi Metode 5C Of Credit Pada Bank. (September). https://doi.org/10.17605/OSF.IO/6U7RP

Oka, K. W. L., Purnamawati, G. A., \& Sinarwati, N. K. (2015). Pengaruh Dana Pihak Ketiga, Penilaian 5c Kredit, Dan Kualitas Kredit Terhadap Keputusan Pemberian Kredit di PT. Bank Pembangunan Daerah Bali Cabang Singaraja. EJournal S1 Ak, 3(1).

https://www.researchgate.net/publication/327688994, Tanggal akses pada 5 Desember 2018 pukul 20.45 WIB

https://www.amalan.com/id/blog/bi-checking-slik-ojk (Tanggal akses 3 Desember 2018)

https://www.amalan.com/id/blog/cara-membaca-idi-historis (Tanggal akses 5 Desember 2018)

https://www.cermati.com/artikel/rasio-kredit-apa-itu-dan-bagaimana-cara-menghitungnya (Tanggal akses 4 Desember 2018).

https://www.cermati.com/artikel/inilah-syarat-agar-pengajuan-kredit-disetujui-bank (Tanggal akses 3 Desember 2018) 